\title{
A Study on the Elongation of Knitting Yarn under a Small Tension
}

\author{
By Muneo Suematsu, Member, TMSJ
}

Faculty of Engineering, Gunma University

\begin{abstract}
The purpose of this article is to discuss the elastic property of knitting yarn under a small tension. I shall study the relation between the elastic property of yarn and that of wool. I advance the theory that the property of knitting yarn is represented by the density of the elastic energy per mass.

Next, I consider the problem of the distribution of the curve of the density of the elastic energy in the same sample. In this case we consider the relation between the distribution of the density of the elastic energy of knitting yarn and the distribution of the density of the elastic energy of the wool in the space of 3 dimensions.

The following are the findings:

(1) The elastic property of the knitting yarn are represented by the density of the elastic energy per mass.

(2) The distribution of the curve of the density of the elastic energy may be adjusted by the mean load of wool.

(3) The form and distribution of the curves of the density of the elastic energy of knitting yarn is determined by the surface of the set of density curves of the elastic energy of wool of which knitting yarn is made.
\end{abstract}

\section{Introduction}

This article discusses the elastic property of knitting yarn under a small tension. This subject seems worth discussing, particularly because the elastic property of knitting yarn depends on the elastic property and on the condition of mixing the wool of which the knitting yarn is made. With this in mind, we have measured the elastic energy of knitting yarn and the fiber of wool.

We will first define the density of the elastic energy per mass which is independent of the natural length of yarn and the wool. Next, we will define the parameter of the elastic property which is independent of the size of fiber of the yarn. After the definition of this parameter, we will define the mean load of the wool which makes up the yarn. Finally, we will consider the relation between the distribution of the load density curves of the elastic energy of yarn and the distribution of the load density curves of wool.

Each sample has a characteristic type of distribution and a characteristic curve form of the load density curves of the elastic energy of yarn. The distribution of the load density curves of the elastic energy of wool is in the neighborhood of the characteristic surface in the space of 3 dimensions. The elastic property of knitting yarn depends directly on the elastic property of wool and on the distribution in the neighborhood of the characteristic surface of wool.

\section{Appatatus Used}

Figure 1 shows the main part of the apparatus used by the author in his experiments in connection with the present study. Wool yarn and a spring balancer are set in the inner

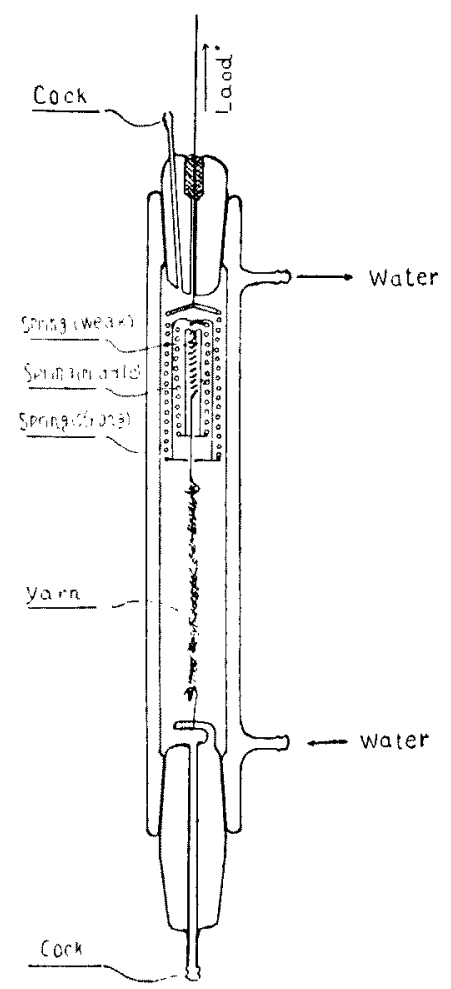

Fig. 1 
cylinder fixed at a constant $15^{\circ} \mathrm{C}$ and the humidity at a constant $75 \%$. The elongation of the yarn wool and of the spring balancer is measured with a chased meter at $1 / 100 \mathrm{~mm}$.

The spring balancer for wool consists of two parallel springs. The weak spring measures a range of 0 to $350 \mathrm{mg}$, the strong spring a range of $350 \mathrm{mg}$ to $8 \mathrm{~g}$. The spring balancer for yarn is made up of three parallel springs. The weak spring measures a range of 0 to $350 \mathrm{mg}$, the middle spring a range of $350 \mathrm{mg}$ to $2 \mathrm{~g}$ and the strong spring a range of $2 \mathrm{~g}$ to $50 \mathrm{~g}$.

\section{Measuring Methods Used}

\section{2-1. Sampling of Yarn and Wool}

We sampled 20 specimens of yarn totalling about $200 \mathrm{~mm}$ in length, drawn from a lot of about $9 \mathrm{~g}, 120 \mathrm{~m}$. Next we decomposed the remaining specimens and measured the maximum length $l$ of the wool. We then selected two points ( $A$ and $B$ )- (see Figure 2 ), [the length between $A$ and $B]>[1.3 \times$ (maximum length $l$ )]. The two points were tied together with nylon and sized synthetic resin.

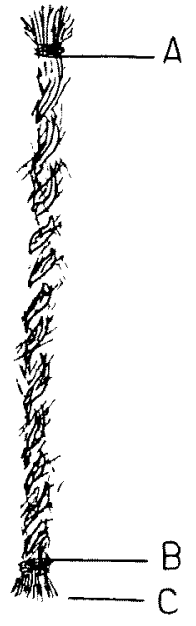

Fig. 2

Finally, we counted the number of fibers of the wool at point $C$ in Figure 2. This number of fibers is called the number of wool. The specimens used are shown in Table 1.

These 20 specimens of yarn were measured for load elongation curve, then decomposed in the simple fiber of the wool. From this mass of wool, we drew and sampled 20 fibers of the wool. We weighed the wool with a microbalance having an arm about $15 \mathrm{mg}$ in weight and $50 \mathrm{~mm}$ in length.

\begin{tabular}{|c|c|c|c|c|c|c|c|c|}
\hline \multirow[b]{2}{*}{ No. } & \multicolumn{2}{|c|}{$\mathrm{T}$} & \multirow{2}{*}{$\begin{array}{c}\mathrm{N}_{\mathrm{i}} \\
\text { Mass } \\
\text { (mg) }\end{array}$} & \multicolumn{2}{|r|}{$\mathrm{S}$} & B & \multicolumn{2}{|c|}{$S_{t}$} \\
\hline & $\begin{array}{l}\text { Mass } \\
\text { (mg) }\end{array}$ & $\begin{array}{c}\text { Number } \\
\text { of } \\
\text { fiber }\end{array}$ & & $\begin{array}{l}\text { Mass I } \\
(\mathrm{mg})\end{array}$ & $\begin{array}{c}\text { Number } \\
\text { of } \\
\text { fiber }\end{array}$ & $\begin{array}{r}\text { Mass } \\
(\mathrm{mg})\end{array}$ & & $\begin{array}{c}\text { Number } \\
\text { of } \\
\text { fiber }\end{array}$ \\
\hline $\begin{array}{l}1 \\
2 \\
3 \\
4 \\
5 \\
6 \\
7 \\
8 \\
9 \\
10 \\
11 \\
12 \\
13 \\
14 \\
15 \\
16 \\
17 \\
18 \\
19 \\
20 \\
21\end{array}$ & $\begin{array}{r}11.50 \\
15.18 \\
14.45 \\
11.58 \\
13.26 \\
11.09 \\
12.67 \\
10.41 \\
12.59 \\
9.25 \\
14.49 \\
11.36 \\
13.68 \\
12.35 \\
14.57 \\
12.82 \\
14.30 \\
12.75 \\
13.65 \\
13.90\end{array}$ & $\begin{array}{r}94 \\
114 \\
75 \\
91 \\
110 \\
109 \\
114 \\
93 \\
81 \\
72 \\
93 \\
88 \\
108 \\
125 \\
107 \\
113 \\
110 \\
91 \\
107 \\
88\end{array}$ & $\begin{array}{r}11.62 \\
9.40 \\
10.61 \\
9.31 \\
10.82 \\
11.98 \\
12.50 \\
9.85 \\
10.30 \\
8.30 \\
10.40 \\
9.65 \\
12.40 \\
9.90 \\
10.35 \\
11.30 \\
10.42 \\
10.30 \\
11.50 \\
10.10\end{array}$ & $\begin{array}{l}42.85 \\
41.15 \\
17.80 \\
16.69 \\
20.34 \\
19.41 \\
18.63 \\
18.10 \\
18.35 \\
18.10 \\
20.10 \\
21.30 \\
16.35 \\
18.40 \\
20.40 \\
21.70 \\
19.00 \\
14.55 \\
20.25 \\
17.25\end{array}$ & 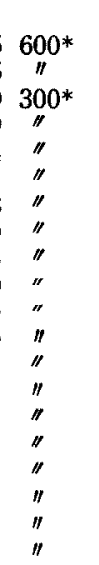 & $\begin{array}{l}19.09 \\
18.58\end{array}$ & $\begin{array}{r}10.00 \\
10.72 \\
12.32 \\
10.41 \\
9.75 \\
11.70 \\
12.41 \\
9.70 \\
9.55 \\
12.75 \\
13.28 \\
11.75 \\
13.24 \\
8.58 \\
7.80 \\
11.47 \\
10.65 \\
9.36 \\
15.05 \\
10.55\end{array}$ & $\begin{array}{l}56 \\
49 \\
70 \\
59 \\
57 \\
80 \\
76 \\
54 \\
65 \\
62 \\
95 \\
63 \\
59 \\
48 \\
51 \\
54 \\
64 \\
81 \\
50 \\
59\end{array}$ \\
\hline
\end{tabular}

\begin{tabular}{|c|c|c|c|c|c|c|}
\hline \multirow[b]{2}{*}{ No. } & \multicolumn{4}{|c|}{$\mathrm{T}_{\mathrm{h}}$} & \multicolumn{2}{|r|}{$\mathrm{N}_{2}$} \\
\hline & $\begin{array}{l}\widehat{\text { Mass }} \\
\text { (mg) }\end{array}$ & $\begin{array}{l}\text { Temper - } \\
\text { ature } \\
\left({ }^{\circ} \mathrm{C}\right)\end{array}$ & $\begin{array}{l}\text { Humidity } \\
(\%)\end{array}$ & $\begin{array}{c}\text { Number } \\
\text { of } \\
\text { fiber }\end{array}$ & $\begin{array}{l}\text { Mass } \\
\text { (mg) }\end{array}$ & $\begin{array}{c}\text { Temper } \\
\text { ature }\end{array}$ \\
\hline $\begin{array}{r}1 \\
2 \\
3 \\
4 \\
5 \\
6 \\
7 \\
8 \\
9 \\
10 \\
11 \\
12 \\
13 \\
14 \\
15 \\
16 \\
17 \\
18 \\
19 \\
20 \\
21\end{array}$ & $\begin{array}{r}9.30 \\
10.10 \\
10.38 \\
11.59 \\
11.71 \\
10.68 \\
8.65 \\
10.38 \\
10.83 \\
11.53 \\
9.37 \\
9.69 \\
11.21 \\
11.40 \\
12.72 \\
10.98 \\
10.00 \\
11.60 \\
8.72 \\
10.24\end{array}$ & $\begin{array}{l}14.5 \\
13.5 \\
15.0 \\
13.0 \\
16.0 \\
13.0 \\
12.5 \\
11.0 \\
15.5 \\
15.0 \\
16.0 \\
14.2 \\
16.0 \\
15.5 \\
15.0 \\
15.2 \\
16.5 \\
18.0 \\
18.5 \\
20.5\end{array}$ & $\begin{array}{l}34.5 \\
50.0 \\
27.0 \\
45.5 \\
41.0 \\
48.0 \\
43.5 \\
41.0 \\
44.0 \\
39.0 \\
53.0 \\
49.5 \\
49.0 \\
40.0 \\
47.0 \\
64.0 \\
57.5 \\
43.0 \\
40.5 \\
40.0\end{array}$ & $\begin{array}{r}77 \\
95 \\
105 \\
109 \\
112 \\
87 \\
95 \\
96 \\
83 \\
103 \\
86 \\
103 \\
106 \\
99 \\
84 \\
93 \\
106 \\
105 \\
93 \\
101\end{array}$ & $\begin{array}{l}15.60 \\
17.18 \\
12.46 \\
15.77 \\
17.19 \\
14.55 \\
15.15 \\
17.15 \\
14.50 \\
14.29 \\
15.48 \\
14.88 \\
14.95 \\
15.55 \\
16.20 \\
14.80 \\
15.49 \\
15.25 \\
15.59 \\
14.89\end{array}$ & $\begin{array}{l}14.0 \\
14.0 \\
14.8 \\
14.5 \\
10.5 \\
13.0 \\
13.0 \\
11.0\end{array}$ \\
\hline
\end{tabular}

\begin{tabular}{|c|c|c|}
\hline No. & $\begin{array}{c}\text { Humidity } \\
(\%)\end{array}$ & $\begin{array}{c}\text { Number } \\
\text { of } \\
\text { fiber }\end{array}$ \\
\hline $\begin{array}{r}1 \\
2 \\
3 \\
4 \\
5 \\
6 \\
7 \\
8 \\
9 \\
10 \\
11 \\
12 \\
13 \\
14 \\
15 \\
16 \\
17 \\
18 \\
19 \\
20 \\
21\end{array}$ & $\begin{array}{l}41.0 \\
41.0 \\
36.0 \\
34.5 \\
18.5 \\
24.5 \\
28.0 \\
22.5\end{array}$ & $\begin{array}{r}105 \\
73 \\
100 \\
109 \\
100 \\
93 \\
107 \\
94 \\
94 \\
93 \\
92 \\
88 \\
116 \\
115 \\
87 \\
74 \\
95 \\
105 \\
123 \\
73\end{array}$ \\
\hline
\end{tabular}

*Round numbers 
2-2. Measuring the Load Elongation Curve

Figure 1 shows yarn and wool set in the inner cylinder having a constant temperature at $15^{\circ} \mathrm{C}$ and a constant humidity at $75 \%$. After being in the inner cylinder for four to five hours the yearn and wool were measured for load elongation curve, under the following conditions:

(1) The yarn was given a load velocity which was increased in velocity at the rate of $1 \mathrm{~g} / \mathrm{min}$. and $0 \leqslant \mathrm{load} \leqslant 50 \mathrm{~g}$.

(2) The wool was given a load, which was increased in tension at the rate of $0.1 \mathrm{~g} / \mathrm{min}$. (speed) and $0 \leqslant 10 a d \leqslant 8 \mathrm{~g}$.

\section{2-3. Measuring the Mass of the Yarn}

We measured the load elongation curve of the yarn, after which we measured the mass of the yarn which constituted the inside of the points $A$ and $B$ which were tied together.

\section{Results of Experiment}

In Figure 3 the curves from B.T.1 $\alpha$ to B.T.1s are the load elongation curve of the same hand-knitting yarn. Those curves are all similar in form and are in the neighbourhood of a curve.

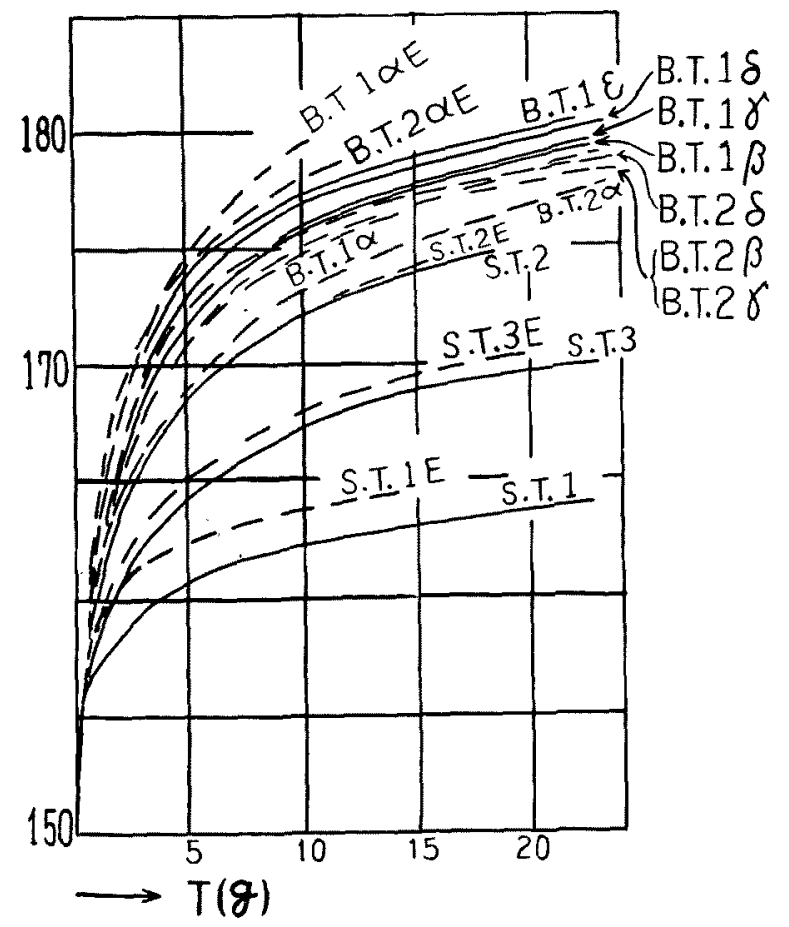

Fig. 3

The curves of S.T.1, S.T.2 and S.T.3 are the load elongation curve of sample $S$ in Table 1. They show that the load elongation curve of the same sample are similar in form but these curves are distributed in a large The elastic energy $E$, which is charged by the elongation of yarn, is independent of the length of yarn.

This elastic energy $E$ is expressed as follows:

$$
E=\int_{l o}^{l} t d l,
$$

where $t$ is a load of the elongation, $l$ is a length of the elongation, and $l_{o}$ is the natural length loadless yarn. The elastic energy $E$ is calculated by the method of the graphical integral.

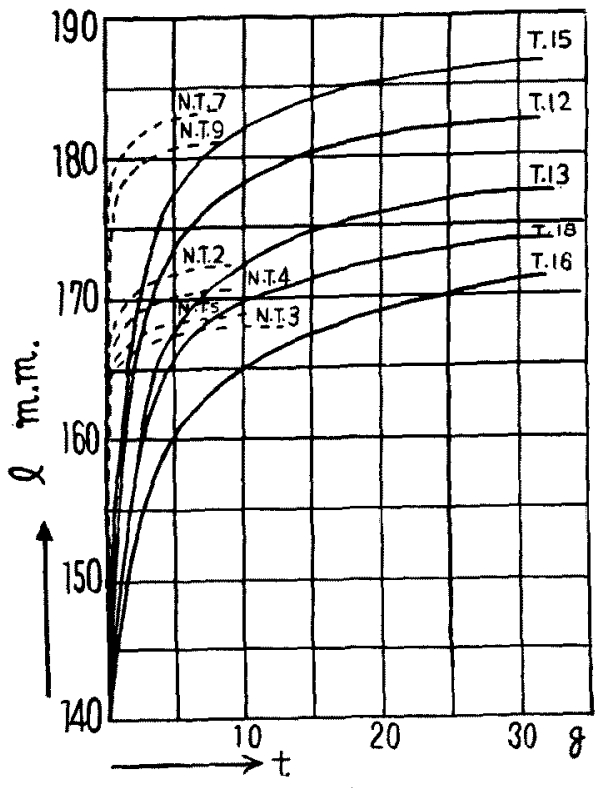

Fig. 4

The curve B.T.1oE is the load elastic energy curve of the curve B.T.1 $\delta$. The curves S.T.1E, S.T. $2 E$ and S.T.3E are the respective load elastic energy curves of the S.T.1, S.T.2 and S.T.3.

The curve set of the load elongation curve of sample $N_{1}$ in Figure 4 shows the following property:

(1) The elongation shows the crimp property for a load of 0 to $5 \mathrm{~g}$.

(2) The elongation is ordinary elastic property for a load of 5 to $10 \mathrm{~g}$.

The curve set of the load elongation curve of sample $T$ shows the following property:

(1) The elongation is the crimp property for a load of 0 to $20 \mathrm{~g}$.

(2) The elongation is ordinary elastic property for a load of 20 to $50 \mathrm{~g}$.

These results show that each sample has a characteristic load elongation curve.

We shall next discuss the density of the elastic energy which is independent of the mass, the length or the size of the fiber of the specimen.

The density of the elastic energy per mass is definded by the following equation: 


$$
W=\frac{E}{M}
$$

where $E$ is the elastic energy of the yarn and the wool, $M$ is the mass of the yarn and the wool. The density of elastic energy per mass is independent of the natural length of the specimen. The density of the elastic energy is the essential parameter of the elastic property of the finite deformable bodies. With the aid of the density of elastic energy per mass, we can compare the elastic property of yarn with the elastic property of wool.

The curves S.T.2 and S.T.3 in Figure 5 are the load density curve of the elastic energy of sample $S$. Hand knitting yarn S.T.2 and S.T.3 are $(4 / 12)$ 's and have a wool content of about 600. The curves S.T.4, S.T.8, S.T.9 and S.T.14 are the load density curve of sample

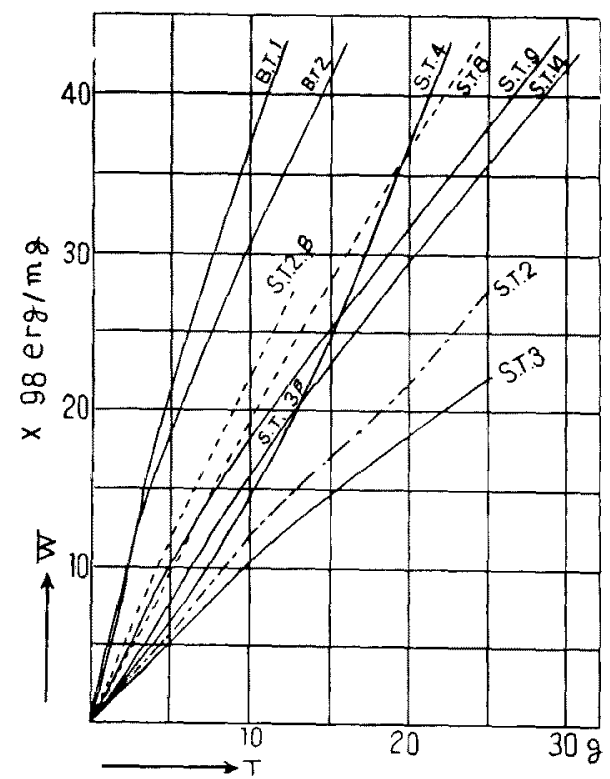

Fig. 5

S.S.T.4, S.T.8, S.T.9 and S.T.14 are $(2 / 12)$ 's and have a wooi content of about 300 . By making the mean load of the wool of yarns S.T.2 and S.T.3 equal to the mean load of yarns S.T.4, S.T.8, S.T.9 and S.T.14, the curves S.T.2 and S.T.3 are transformed into curves S.T.2 $\beta$, and S.T.3 $\beta$, and the curves S.T.2 $\beta$ S.T.3 $\beta$ come near curves S.T.4, S.T.8, S.T.9 and S.T.14. Even if a sample contains yarns of different thicknesses, the density curves of their elastic energy can be made even by making the mean load of wool uniform.

In Figure 6, the set of curves is the load density curves of sample $N_{1}$, and the mean curve is the mean of those curves at each load.

In Figure 7, the set of curves is the set of load density curves of sample $T$.
The set of curves in Figure 8 is the set of curves of the load density of sample $S_{t}$ and the mean curve is the mean of those curves at each load.

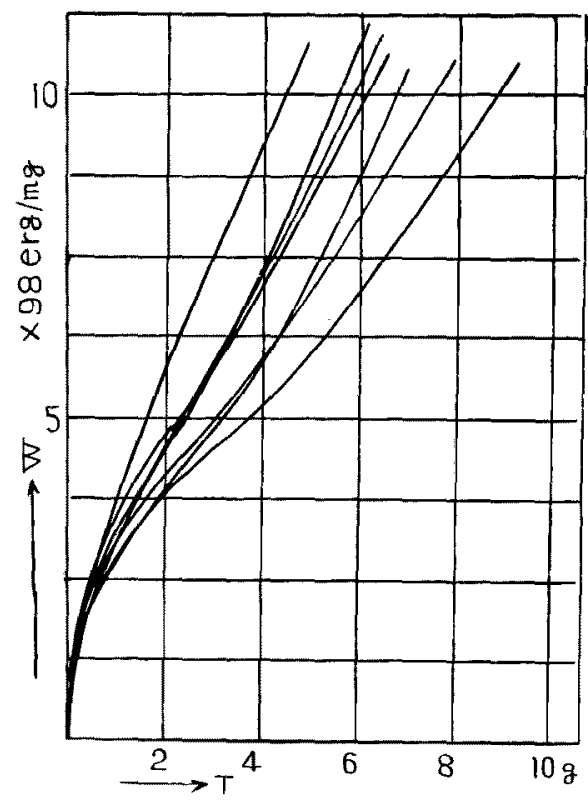

Fig. 6

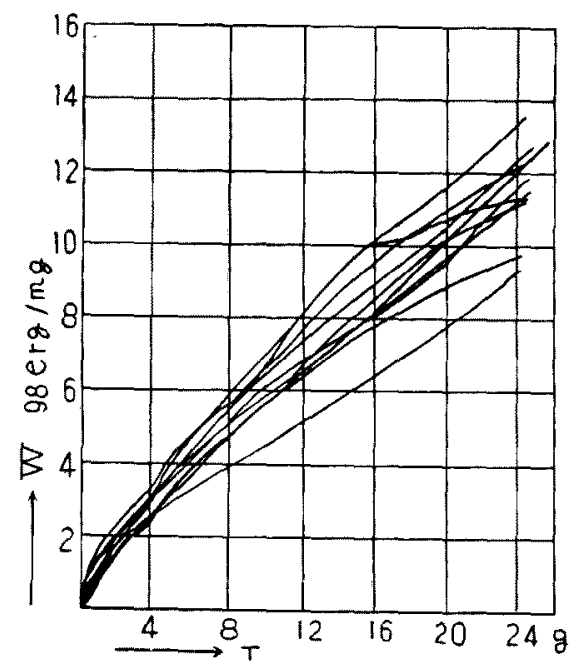

Fig. 7

The set of curves in Figure 9 shows a set of load density curves of sample $N_{2}$ and the mean curve of this set.

The set of curves in Figure 10 shows a set of load density curves of sample $T_{h}$ and the mean curve of this set.

The larger the load, the larger the range in which the sets of curve from Figure 6 to Figure 10 fluctuate. Here we introduce the coefficient of variation $V$. 


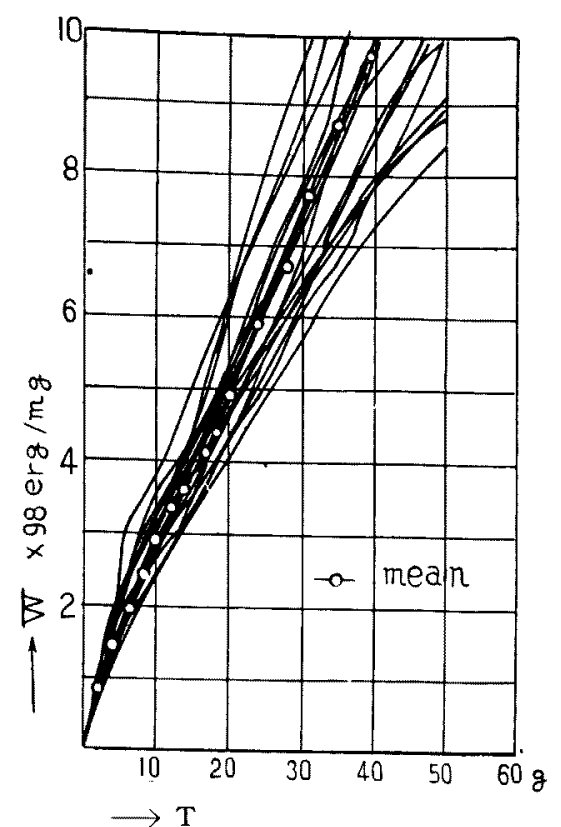

Fig. 8

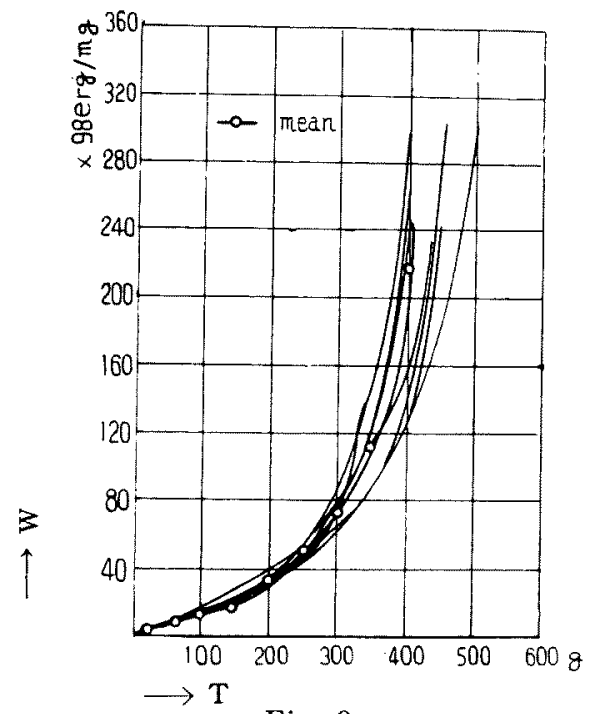

Fig. 9

$$
V=\frac{\sigma}{\bar{W}}
$$

where $\sigma$ is the standard deviation of the density of the elastic energy at each load, and $W$ is the mean of the density of the elastic energy at each load. The coefficient of variation $V$ is shown in Figures 11 and 12 . The curves in these figures are in the fluctuation range of $0.08 \sim 0.22$ and may, therefore, be assumed to be of about equal accuracy in measurement.

Here again let us probe the elastic property of wool that makes up yarn. We define the natural length of wool as the distance to the origin from the point of intersection of $l$ axis and the extension of the ordinary elastic part of the load elongation ${ }^{[1]}$. Then we define the line density $\rho$ of wool as:

$$
\rho=\frac{M}{l}
$$

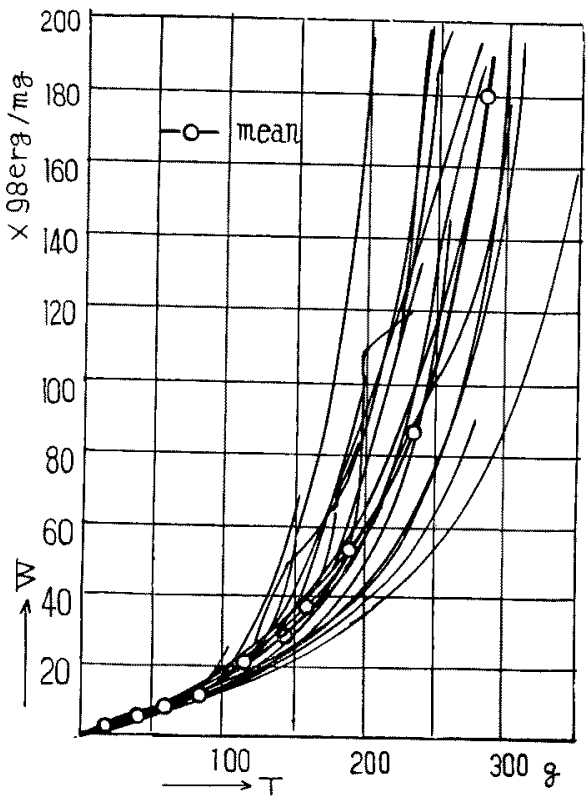

Fig. 10

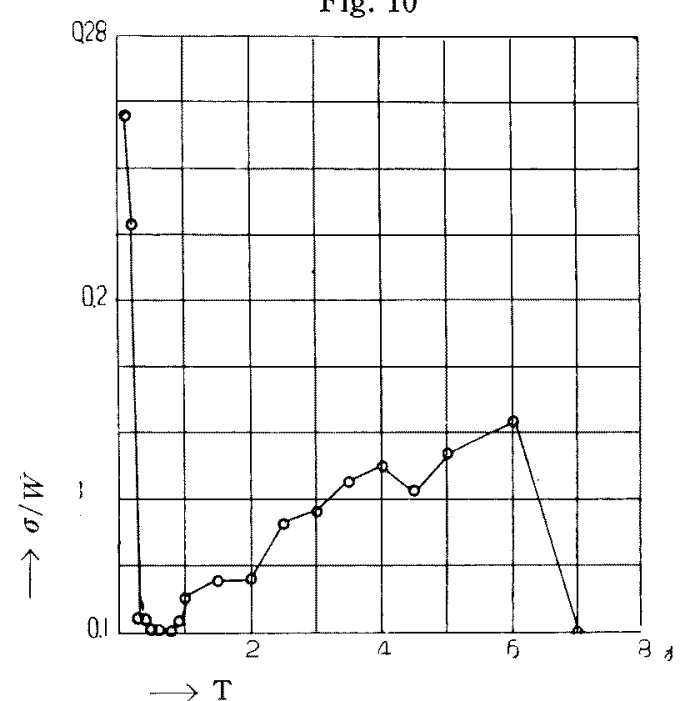

Fig. 11

where $l$ is the natural length of wool, and $M$ is the mass of wool. Those resultes are repressented by three solid spaces $(\rho, t, W)$, where $\rho$ is the line density of the wool, $t$ is the load, $w$ is the density of the elastic energy of wool. From the figure just measured we see that every of the load density curves of wool is in the neighborhood of the simple characteristic surface of each sample.

The set of curves in Figure 13 is the set of sample $N_{1}$, where the $X$ axis is the line density of wool, the $Y$ axis is the load, and $Z$ axis is the density per mass of elastic energy. The wool of same $N_{1}$ is distributed in $3 \times$ $10^{-3}<\rho<9 \times 10^{-3} \mathrm{mg} / \mathrm{cm}$, a concentrated type of distribution.

The set of curves in Figure 14 is the set of the curves of sample $T$. These curves are distributed in $5.5 \times 10^{-3}<p<12 \times 10^{-3} \mathrm{mg} / \mathrm{cm}$, a uniform type of distribution. 


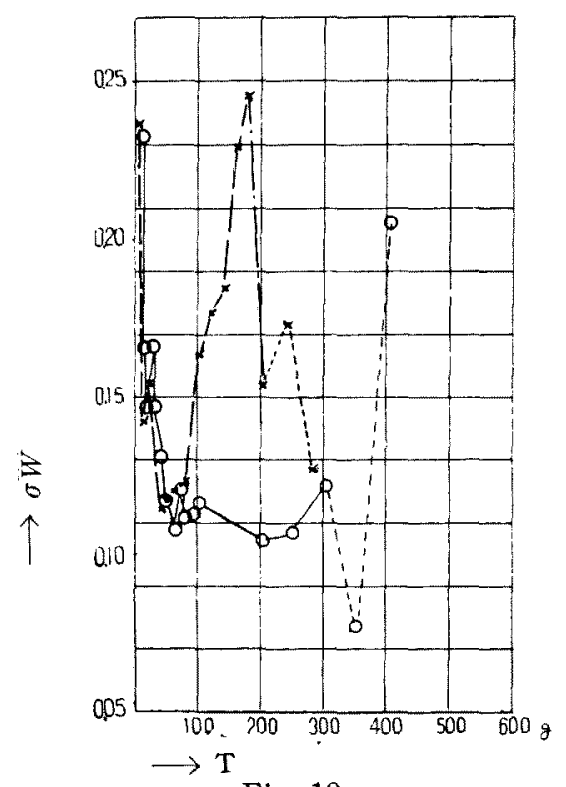

Fig. 12

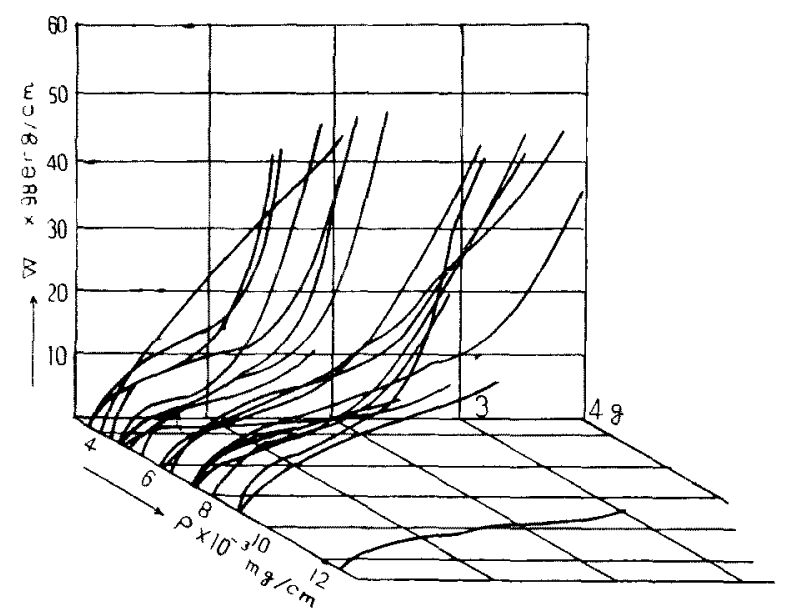

Fig. 13

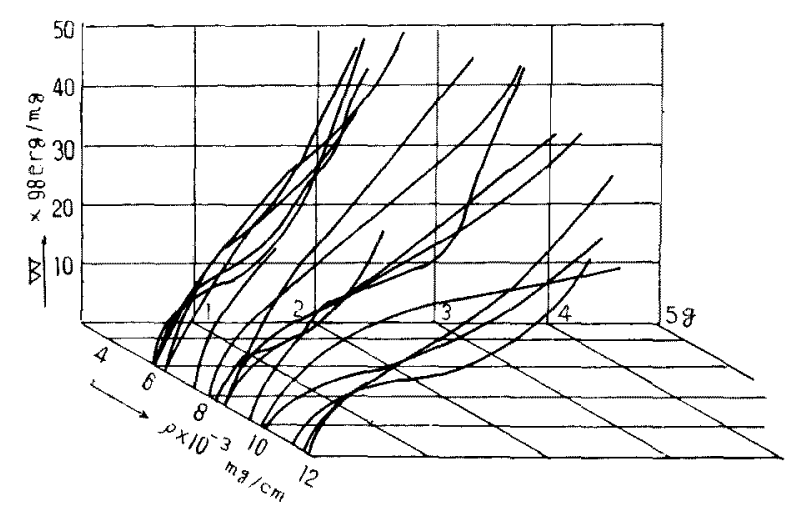

Fig. 14

The set of surves in Figure 15 is the set of the curves of sample $S_{t}$. These curves are distributed in the range of $3 \times 10^{-3}<\rho<13 \times$ $10^{-3} \mathrm{mg} / \mathrm{cm}$, a normal type of distribution.

The set of curves in Figure 16 is the set of the curves of sample $N_{\text {... }}$. These curves are

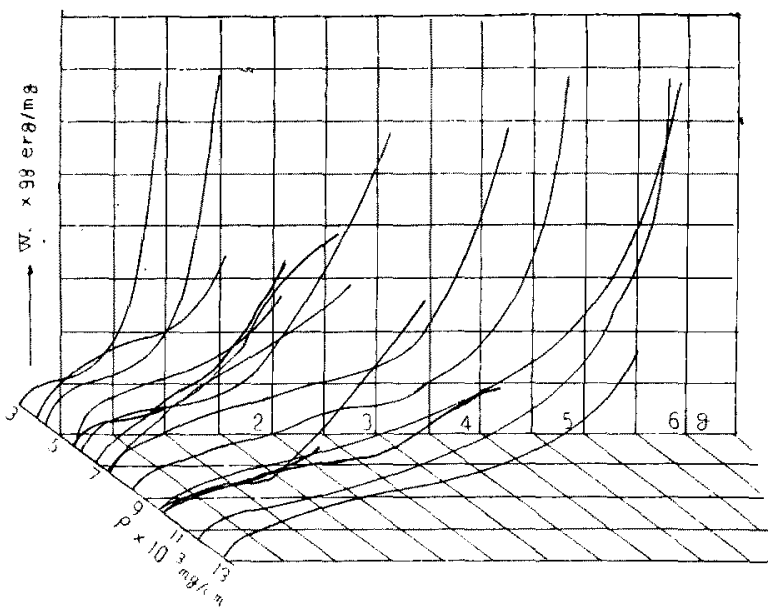

Fig. 15

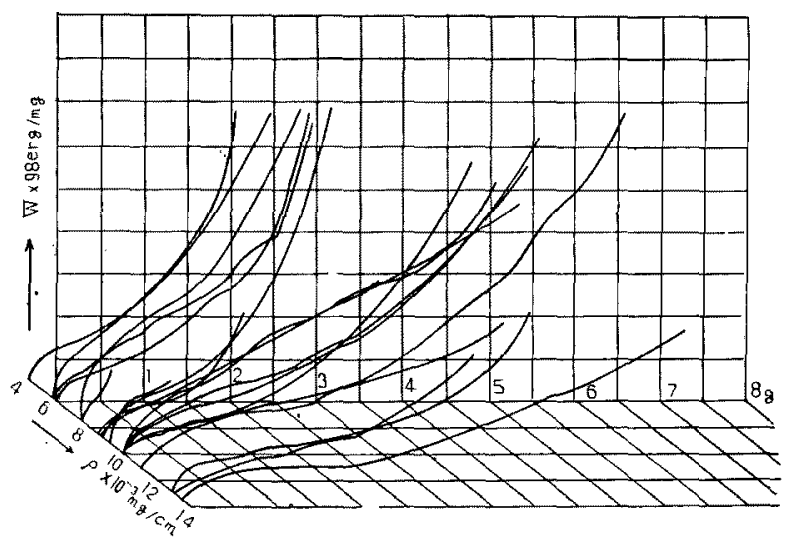

Fig. 16

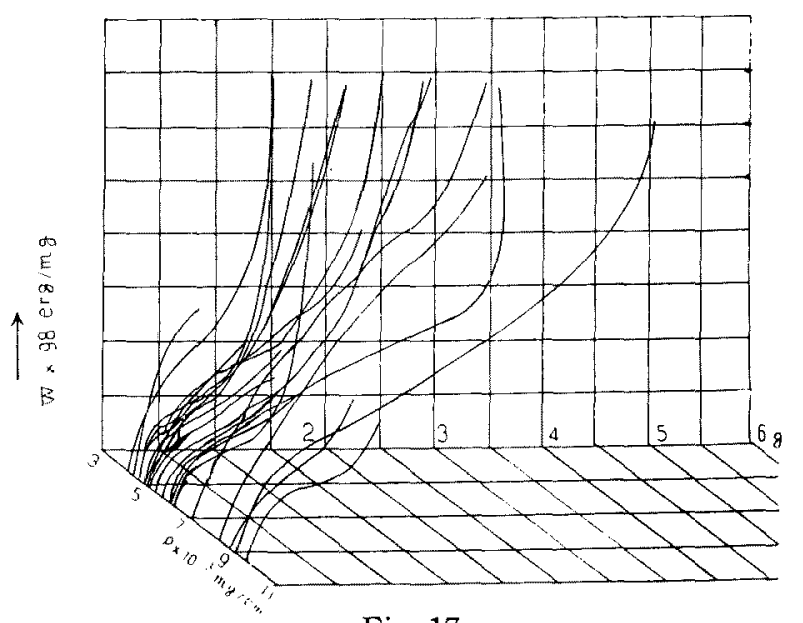

Fig. 17

distributed in the range of $4 \times 10^{-3}<\rho<14 \times$ $10^{-3} \mathrm{mg} / \mathrm{cm}$, again a normal type of distribution.

The set of curves in Figure 17 is the set of the curves of sample $T_{l}$. These curves are distributed in the range of $4 \times 10^{-3}<\rho<10$ $\times 10^{-3} \mathrm{mg} / \mathrm{cm}$, a type of distribution which is concentric at point $5 \times 10^{-3} \mathrm{mg} / \mathrm{cm}$.

With the aid of these sets, we shall study the relation between the curve set of yarn and the curve set of wool. The number of fibers of 
the wool of these samples is in the range of $70<$ $n<100$. Therefore, if the load of the yarn is $50 \mathrm{~g}$, then the mean load of the wool is about $144 \mathrm{mg}$, a load of insufficient degree to snap the wool. We can assume, then, that the elastic energy is equal of the energy applied for the elongation of the wool. Therefore, we can compare the curve sets of the yarn with the curve sets of the wool.

The sets of curves in Figures 6 and 13 are two sets of curves of the load density curves of the elastic energy of sample $N_{1}$. In Figure 13 , the line density is concentrated over a small range, but the curve form of the yarn is the same in type as the curve form of the wool. The curves in Figure 6 are distributed over a large range $(7 \sim 13 \mathrm{erg} / \mathrm{mg})$ at the load $6 \mathrm{~g}$.

Figures 7 and 14 are two sets of curves of sample $T$. The type of the curve set of yarn is shaped by the curve form and distribution of wool. The wool is distributed in uniform type, i. e., $5.5 \times 10^{-3}<\rho<12 \times 10^{-3}$. The curves in Figure 7 are in a small striped range.

The sets of curves in the Figures 8 and 15 are two curve sets of sample $S_{t}$. They show similarity of curve form for wool and yarn.

The set of curves in Figures 9 and 16 are two curve sets of sample $N_{2}$. The rate of increase of the curve of the wool is small; so is the rate of increase of the curve of the yarn.

The set of curves in the Figures 10 and 17 are two curve sets of sample $T_{h}$. The distribution of the curves of yarn is in a large striped range and the rate of increase of the curve of yarn is large. This results from the curve form and the curve distribution of the weak wool in Figure 17.

Therefore, the knitting yarn shows the following properties:

(1) If the load density curves of the elastic energy of wool are concentrated over a small range, then the curve form of knitting yarn made of that wool is similar in curve form to the load density curve of the elastic energy of the wool. And the load density curves of the elastic energy of the yarn are distributed in a large striped range. (See Figures 6, 13, and Figures 10, 17.)

(2) If the load density curves of the elastic energy of wool are distributed in the normal or uniform type over a large range, then the load density curves of the elastic energy of the yarn made of that wool show the mean property of the load density curves of the elastic energy of the wool. And these curves of the yarn are distributed in a small striped range. (See Figures 7, 14, Figures 8, 15, Figures 9,16.)

\section{Conclusions}

(1) Each sample of knitting yarn and hand knitting yarn has a characteristic form of load elongation form, if the parameter of the load is the mean load of wool

(2) The elastic property of knitting yarn can be represented by the load density curves of the elastic energy if the elastic energy is calculated by the load elongation curve and is independent of the length of yarn.

(3) The load density curves per mass of elastic energy are in a small striped range, if the load is modulated to the mean load of wool.

(4) The load density curves of the elastic energy of yarn per mass is related to the curve form of the load density curves of the elastic energy per mass of wool and the distribution of these curves of the wool.

We are indebted to the Minister of Educa tion of Japan for the financial support given 1954 to the author's experiments.

\section{Liturature cited}

[1] M. Suematsu; J. Text. Mach. Soc., Japanese edition, Vol 7, No. 3, pp. 26 31 (1954.) 